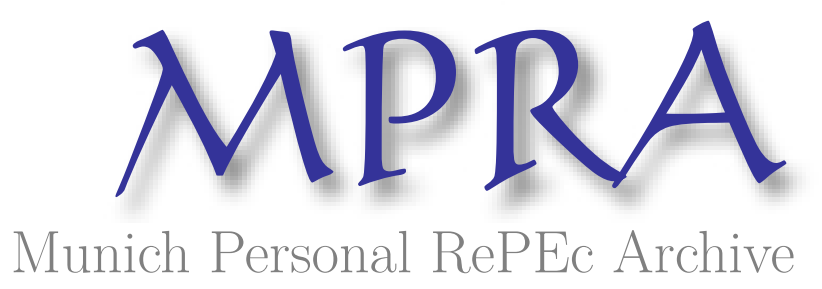

\title{
Measuring monetary policy and its impact on the bond market of an emerging economy
}

Sensarma, Rudra and Bhattacharyya, Indranil

October 2015

Online at https://mpra.ub.uni-muenchen.de/81067/

MPRA Paper No. 81067, posted 31 Aug 2017 16:28 UTC 


\title{
Measuring monetary policy and its impact on
}

\section{the bond market of an emerging economy}

\author{
Rudra Sensarma and Indranil Bhattacharyya*
}

\begin{abstract}
In view of multiple instruments used by many central banks in emerging market economies, we derive a composite measure of monetary policy for India and assess its impact on the yield curve. Our results show that while monetary policy has the dominant impact among macroeconomic variables on the entire term structure, it is particularly strong at the shorter end and on credit spreads. Shifts in the level of the government yield curve and credit spreads also lead to changes in monetary policy. In terms of robustness, our measure performs better than a narrative based measure of monetary policy available in the literature.
\end{abstract}

Key words: Term structure, yield curve, monetary policy, SVAR

JEL Classification: C51, E44, E52

\footnotetext{
* Sensarma is Associate Professor at the Indian Institute of Management Kozhikode, India while Bhattacharyya is Assistant Adviser in the Reserve Bank of India, Mumbai. The views expressed in the paper are those of the authors and not of the institutions to which they belong. The usual disclaimer applies.

Corresponding author: Indranil Bhattacharyya. Address: Department of Economic and Policy Research, Reserve Bank of India, Fort, Mumbai - 400001, India. Phone: +91(22)22602413. Email: ibhattacharya@rbi.org.in.
} 


\section{Introduction}

The recently developing macro-finance literature synthesizes emerging insights from the overlapping areas of macroeconomics and financial economic theory to explain fluctuations in economic activity. In standard macro models, the entire financial sector is often represented by a single interest rate with no role for financial frictions. Similarly, finance models focus solely on the consistency of asset prices across markets with little regard for the underlying economic fundamentals. In order to bridge this gap, a macro-finance perspective is necessary in economic modelling, particularly in the post-crisis environment when such linkages are posing a significant challenge, both to economists and policy makers.

While the evolution of economic fundamentals across phases of the business cycle is caused by the interplay of several real and monetary factors, monetary policy plays a distinct role in shaping macroeconomic outcomes by influencing the cost of credit. In this regard, the impact of monetary policy on interest rates is critical due to its influence on the aggregate level of spending and investment in the economy. In term-structure models, the shape of the yield curve has been characterised by its latent factors viz., level, slope and curvature (Knez et al, 1994; Dai and Singleton, 2000). The burgeoning literature has examined how macroeconomic shocks work through monetary policy to change the shape of the yield curve (Diebold et al., 2005; Evans and Marshall, 1998, 2007). For instance, while changes in the market's perception of the inflation target shifts the level of the yield curve in inflation targeting regimes, monetary policy shocks lead to a decline in its slope (Diebold et al., 2006; Rudebusch and Wu, 2008). Moreover, curvature changes occur when market participants revise their expectation on yields of different maturities (Giese, 2008). In these models, while the inflation target shock is found to account for most of the variation in the level, the monetary policy shocks dominate the variations in slope and curvature (Bekaert et al., 2010). 
While there is a large body of literature pertaining to developed markets on this issue, the paucity of similar work in the context of emerging and developing economies is rather striking. Given multiple policy objectives, market imperfections, inadequacy of institutions and the predominance of the traditional banking channel in many of these economies, a deeper understanding of monetary policy impact on the term structure and credit spreads are essential for overall financial market development. One of the factors that renders this task complicated in emerging markets is the prevalence of several monetary policy instruments catering to multiple policy objectives (prominent examples being China, India and Latin America), ${ }^{1}$ which makes it difficult to identify one single instrument as representative of policy stance. The objective of the present paper is to develop a method of overcoming this problem by using India as a case study.

The choice of India is motivated by several reasons. First, India is the third largest economy in terms of purchasing power parity and is one of the fastest growing economies in the world with an average real GDP growth of $7.3 \%$ over the last decade (2001-10). Even as the global economy was plagued by all pervasive depression fears, India recorded an impressive growth of $7.8 \%$ in the post-crisis period (2009-11). Second, it has a well regulated financial system which emerged relatively unscathed from the global financial crisis. Third, although a primarily bank-based system, India has a vast and varied financial market infrastructure necessary for mobilizing resources to sustain the growth momentum. Fourth, in pursuit of multiple monetary policy objectives viz., (i) supporting growth, (ii) ensuring price stability and (iii) preserving financial stability, India uses several policy instruments, simultaneous changes in which are often seen to be contradictory from a market perspective. Finally, it is making a transition since 1991 from a partially regulated to a market economy where the transmission mechanism of monetary policy is still evolving and, therefore, remains relatively under-researched.

\footnotetext{
${ }^{1}$ Burdekin and Siklos (2008), Bhattacharyya and Sensarma (2008) and Montoro and Moreno (2011) discusses the use of reserve requirements along with policy rates in China, India and Latin America.
} 
In the Indian case, an appraisal of the impact of monetary policy on the yield curve is particularly interesting on account of two factors. First, being the monetary authority in addition to the debt manager of the government means that the central bank viz. the Reserve Bank of India (RBI) often has to balance conflicting purposes. In its role as the debt manager, the RBI's aim is to mobilise resources for the government at low interest rates. Such low rates, however, may not be necessarily compatible with the objective of price stability. Moreover, signals emanating from the RBI in its dual role may confuse market participants about the real intent of policy and destabilise expectations about the future, particularly with the persistence of chronic fiscal deficits. ${ }^{2}$ For instance, a soft interest rate regime pursued by the monetary authority may be interpreted by the market as a precursor to large government borrowings and worsening fiscal situation. On the other hand, monetary tightening may also appear as neutralising the impact of loose fiscal policy. Second, as the RBI uses several policy instruments, it is difficult to characterise any single instrument as being indicative of the stance of policy at any point of time. Cumulatively, these two factors have resulted in few relevant empirical studies on India.

In this paper, we adopt a macro-finance approach to study the impact of monetary policy on the term structure of the bond market. In the Indian context, there are few papers that are related to our work. Kanjilal (2011) investigates the dynamic linkages between the estimated parameters of a zero coupon yield curve and macroeconomic variables and finds that there exists strong causality from latent factors to macroeconomic factors, but the causality in the opposite direction is found to be weaker. Kanjilal (2013) shows that more than 90 per cent of the variation in yield curve for the period 1997-2011 is explained by the level factor asserting that yield curve movements mainly reflect the changes in monetary policy. In contrast, the study by Sahoo and Bhattacharyya (2012) used the market proxies of latent factors of the yield curve and found that

\footnotetext{
${ }^{2}$ The average gross fiscal deficit of the Government, as a proportion of GDP, was 7.8\% during the period 2000-10.
} 
while policy changes have the dominant impact on level and curvature of the yield curve, exchange rate movements largely determines its slope.

This study is distinct in several ways. First, unlike Kanjilal $(2011$; 2013) who uses call money rate as a policy instrument, we develop a composite monetary policy index as a summative measure of policy stance by using principal component analysis - possibly a first-time application of this popular technique in measuring monetary policy - based on the actual policy instruments used by the Reserve Bank of India. In this regard, while Sahoo and Bhattacharyya (2012) uses a narrative based measure of monetary policy available in the literature (e.g. Boschen and Mills, $1991 ; 1995)$, our summative measure is superior as it is free from subjectivity bias in interpretation of policy signals. Robustness checks demonstrate that our measure have superior diagnostics as compared to the narrative based index. Second, while Kanjilal estimated the level, slope and curvature from a large number of maturities, we argue that most of these maturities are illiquid; therefore, their yields do not have much information content. Instead, we calculate the standard market proxies for level, slope and curvature, ${ }^{3}$ using yields from the three most liquid maturities viz., 1, 5 and 10 years. Third, we consider the impact of monetary policy on the yield curve of the bond market - both government and corporate bonds. As a result, our study analyses the behaviour of credit spreads and risk premia to monetary policy shocks in contrast to Sahoo and Bhattacharyya (2012) which is limited to risk-free government bonds only.

We estimate a structural vector autoregression (SVAR) model, based on standard macroeconomic variables and the three underlying factors of the yield curve. We use the PCI to assess the impact of monetary policy on the government yield curve, the corporate yield curve and the resulting credit spreads. Later, we test the robustness of our results using a generalised impulse response framework (Pesaran and Shin, 1998). Our main finding is that while monetary policy

\footnotetext{
${ }^{3}$ Kanjilal (2013) also calculated empirical proxies using the 3-month, 1-year and 10-year yields which, however, are not equally spaced maturities and therefore the usual curvature formula is not appropriate (see Giese, 2008 for more on this). By using equidistant maturities, we are able to avoid this problem.
} 
has stronger effects at the short end of the term structure on both segments of the bond market, it has a relatively stronger impact on credit spreads in the medium term. Our results demonstrate that despite large government borrowings, the Indian bond market remains substantially responsive to monetary policy signals. We also find that the level of the government yield curve and credit spreads have a significant impact on monetary policy decisions. The main contribution of this study is that it offers a convenient approach of evaluating monetary policy in economies using multiple instruments.

The structure of the paper is the following. Section 2 presents a framework of measuring monetary policy with multiple instruments. The econometric methodology is introduced in Section 3. Section 4 gives a synoptic view of the Indian bond market and presents the macroeconomic data and yield curve. The results and their implications are discussed in Section 5. The concluding section summarise the key findings.

\section{Measuring Monetary Policy with Multiple Instruments - A Suggested Framework}

In most developed economies where price stability was the sole objective of monetary policy in the pre-crisis period, a short-term interest rate was usually the preferred instrument of policy. Recent research, however, indicate that reserve requirements can support the price stability objective if financial frictions are important in the economy. Consequent to the global financial crisis, financial stability has assumed primacy for many central banks. In this context, use of reserve requirements may lead to substantial improvements in the policy outcome if the central bank is bestowed with the additional responsibility of ensuring financial stability (Glocker and Towbin, 2012).

In the absence of a single policy objective and a single instrument, the RBI - like many emerging market central banks - employs multiple instruments of monetary policy which are often used simultaneously. During the period of our study, policy adjustments were made through changes in the repo rate (the rate at which banks borrow funds from the RBI), the reverse repo 
rates (the rate at which banks place their funds) and the cash reserve ratio (mandatory reserves that banks hold with the RBI). Simultaneous changes of several instruments are, however, prone to misinterpretation errors. ${ }^{4}$ Moreover, it precludes the identification of any one instrument as the policy measure for our analysis. We overcome this problem by developing a policy index that incorporates these three instruments. We apply principal components analysis to construct a statistically derived index referred to as the principal components index (PCI). Later, in a discussion on robustness, we compare the results based on the PCI with an alternative index referred to as the narrative based index (NBI).

Principal components analysis has been used extensively for examining relationships among several quantitative variables. It has been used earlier in the monetary policy literature to summarise information on a large number of macroeconomic variables (Ang and Piazzesi, 2003), market interest rates of different maturities (Musard-Gies, 2006) and bond yields of different maturities (Evans and Marshall, 1998, 2007). To the best of our knowledge, this is the first application of principal components analysis for summarising information on multiple policy instruments in order to derive a single measure of monetary policy.

The principal components that are formed are uncorrelated linear combinations of the three monetary policy instruments with the weights equal to the Eigen vectors of the correlation or the covariance matrix of the mean-centred data. The first principal component by construction explains the maximum variation (given by the Eigen values) in the underlying data set with the others explaining the remaining variation. The contribution of each original variable to the first principal component determines the importance of the original variables in total variation of the

\footnotetext{
${ }^{4}$ For instance, an increase in the repo rate accompanied by a reduction in CRR may be interpreted as confusing by the market. However, the net impact on the cost of funds would depend on the liquidity effect of higher cost of borrowing from the RBI through the repo window and greater resources available to banks from the release of impounded balances through reduction in CRR.
} 
data. We construct principal components of the three instruments and use the first principal component as a monetary policy index, which we refer to as the PCI (see details in Section 5).

\section{Econometric Methodology}

We estimate a structural vector autoregression (SVAR) model that includes the standard macroeconomic variables of output, price and exchange rate along with the variables of our interest viz., monetary policy index and shape of the relevant yield curve. We use the Index of Industrial Production (IIP) as a proxy for output in the absence of monthly data on GDP, which is the standard practice in most studies on India (e.g. Bahmani-Oskooee and Mitra, 2010 and Sahoo and Acharya, 2010). Price movements are captured by the Wholesale Price Index (WPI) while exchange rate is represented by the trade weighted nominal effective exchange rate (NEER). ${ }^{5}$ The choice of NEER is appropriate given that the RBI looks at a basket of currencies (not solely the US dollar) to monitor orderly movements and in order to curb speculative activities in the foreign exchange market. In addition to these three macroeconomic variables, we use the summative measure of monetary policy discussed above. Finally, we include the shape of the relevant yield curve proxied by its level, slope and curvature.

This gives us a SVAR model with the following variables: IIP, WPI, PCI, NEER, SLOPE, LEVEL, CURVATURE where PCI refers to the monetary policy index based on principal components and the last three variables represent the shape of the yield curve. The SVAR model has the following form

$\mathrm{Ay}_{\mathrm{t}}=\mathrm{A}_{1} * \mathrm{y}_{\mathrm{t}-1}+\ldots+\mathrm{A}_{\mathrm{p}} \mathrm{y}_{\mathrm{t}-\mathrm{p}}+\mathrm{B} \varepsilon_{\mathrm{t}}$

$\varepsilon$ represents the structural errors, $\mathrm{p}$ is the lag length ${ }^{6}$ and the coefficient matrices represent structural coefficients. The reduced form VAR can be represented as:

\footnotetext{
${ }^{5}$ All these variables are taken in logarithmic form and IIP is also de-seasonalised by X-12-ARIMA.

${ }^{6}$ One common approach is to take p as 4 with quarterly data and 12 with monthly data. In our case, that would leave us with limited degrees of freedom. Therefore we choose p by relying on the Schwartz information criteria which gave an optimal lag length of 1 for all the estimated models.
} 
$\mathrm{y}_{\mathrm{t}}=\mathrm{A}_{1} \mathrm{y}_{\mathrm{t}-1}+\ldots+\mathrm{A}_{\mathrm{p}} \mathrm{y}_{\mathrm{t}-\mathrm{p}}+\mathrm{u}_{\mathrm{t}}$

Comparing (1) and (2), the reduced form residuals can be recovered from the structural model as $\mathrm{u}=\mathrm{A}^{-1} \mathrm{~B} \varepsilon_{\mathrm{t}}$

Solving this equality requires a set of zero restrictions on the A and B matrices. One way of doing this is to assume that $\mathrm{A}$ is an identity matrix and impose at least $\mathrm{K}(\mathrm{K}-1) / 2$ restrictions on the $\mathrm{B}$ matrix where $\mathrm{K}$ is the number of variables in the model (Amisano and Giannini, 1997).

The identifying restrictions give us the required relationship between the structural and reduced form shocks i.e. $\varepsilon=\mathrm{Bu}$. Accordingly, we have

$\left(\begin{array}{l}\varepsilon_{\text {IIP }} \\ \varepsilon_{\text {WPI }} \\ \varepsilon_{\text {PCI }} \\ \varepsilon_{\text {NEER }} \\ \varepsilon_{\text {LEVEL }} \\ \varepsilon_{\text {SLOPE }} \\ \varepsilon_{\text {CURVATURE }}\end{array}\right]=\left(\begin{array}{ccccccc}\mathrm{b}_{11} & 0 & 0 & 0 & 0 & 0 & 0 \\ 0 & \mathrm{~b}_{22} & 0 & 0 & 0 & 0 & 0 \\ 0 & 0 & \mathrm{~b}_{33} & 0 & 0 & 0 & 0 \\ 0 & \mathrm{~b}_{42} & \mathrm{~b}_{43} & \mathrm{~b}_{44} & 0 & 0 & 0 \\ 0 & 0 & \mathrm{~b}_{53} & \mathrm{~b}_{54} & \mathrm{~b}_{55} & 0 & 0 \\ 0 & 0 & \mathrm{~b}_{53} & \mathrm{~b}_{54} & 0 & \mathrm{~b}_{66} & 0 \\ 0 & 0 & \mathrm{~b}_{53} & \mathrm{~b}_{54} & 0 & 0 & \mathrm{~b}_{77}\end{array}\right)\left(\begin{array}{l}\mathrm{u}_{\mathrm{IIP}} \\ \mathrm{u}_{\mathrm{WPI}} \\ \mathrm{u}_{\mathrm{PCI}} \\ \mathrm{u}_{\mathrm{NEER}} \\ \mathrm{u}_{\text {LEVEL }} \\ \mathrm{u}_{\mathrm{SLOPE}} \\ \mathrm{u}_{\mathrm{CURVATURE}}\end{array}\right)$

The B matrix above implies the following over-identifying restrictions. The first row indicates that IIP is not contemporaneously affected by other variables (as all $b$ coefficients except for $b_{11}$ are zero) assuming a lead-lag relationship between output and other macroeconomic variables. This can be justified on the grounds that financial market movements impact on the real economy over a period. Accounting for staggered price adjustments, the second row indicates that WPI is not contemporaneously affected by other variables (as all b coefficients except for $b_{22}$ are zero). The third row implies that PCI is not contemporaneously affected by other variables (as all $\mathrm{b}$ coefficients except for $b_{33}$ are zero) as monetary policy suffers from decision and implementation lag, given that information on IIP and WPI are available only after some time. The fourth row 
indicates NEER is contemporaneously affected by WPI, PCI and NEER (b coefficients for WPI, PCI, NEER are non-zero and those for IIP and YIELD are zero) as the foreign exchange market reacts quickly to new information. The fifth to seventh rows indicate that the yield variables are not contemporaneously affected by IIP, WPI but are contemporaneously affected by PCI and NEER (b coefficients for PCI, NEER are non-zero and those for IIP, WPI, LEVEL, SLOPE and CURVATURE are zero). ${ }^{7}$ This is because banks - the key players in the bond and foreign exchange markets - are known to react quickly to monetary policy changes and cross-currency movements in order to hedge their portfolios. We failed to reject the likelihood ratio tests for overidentification at reasonable levels of significance. The model is estimated using a maximum likelihood method (see Amisano and Giannini, 1997). ${ }^{8}$ Subsequently, the impulse responses and forecast error variance decompositions are obtained to examine the role of monetary policy in explaining variations in the term structure. Later, we consider an alternative identification scheme as a robustness check to ensure that our results are invariant to the chosen scheme.

\section{Environmental Context and Data}

Since the mid-1990s, there has been a consistent increase in the size of the government bond market in India in tandem with the growth in borrowings of both the Central and the State Governments. For instance, the combined market borrowing of the Government (Centre plus States) has increased from Indian Rupee (INR) 8,667 billion in 2000-01 to INR 50,924 billion in 2009-10, a staggering compound annual growth of $21.7 \% . .^{9}$ During this period, average daily

\footnotetext{
${ }^{7}$ Data on both IIP and WPI come with a lag and hence cannot be used by market players in their bond trading strategies. However PCI and NEER are real time information which have immediate bearing on bond yields.
}

${ }^{8} \mathrm{We}$ consider all variables in levels as differencing them would lead to loss of information on their relationship (Sims, 1980; Doan, 2000) and VAR estimates are consistent even when unit roots are present (Sims, Stock and Watson, 1990). In any case, our main variable of interest i.e. PCI is stationary with an ADF test statistic of -2.68 which is greater in absolute terms than the $5 \%$ critical value of -1.94 . Therefore, we feel it is not meaningful to take its first difference or to consider its long run relationship with the other variables in a cointegrating framework.

\footnotetext{
${ }^{9}$ The Indian fiscal and financial year is April to March.
} 
turnover in the secondary market for Central Government dated securities increased from INR 28 billion to INR 139 billion.

Although investor preference has generally been for short-term maturity, efforts to extend the maturity structure resulted in the weighted average maturity of debt of the Central Government almost doubling from 5.7 years in 1995-96 to 11.2 years in 2009-10. However, the formation of the yield curve is still at an evolving stage with liquidity being confined only to a few maturity buckets viz., 1, 5 and 10 years, reflecting market segmentation. Consequently, these three maturities have become the benchmark for short, medium and long term paper, respectively. Therefore, we use yields for these three maturities to construct standard empirical proxies of the shape of the yield curve (Bekaert et al, 2010) viz., (i) level (average of 1-year, 5-year and 10-year yields); (ii) slope (spread of 10-year over 1-year); and (iii) curvature (1-year plus 10-year minus twice of 5-year yield $)^{10}$. These proxies closely correspond to the shape of the yield curve estimated using the Nelson-Siegel method (Ang and Piazzesi, 2003; Diebold et al., 2006).

While the government securities market is fairly well developed, the corporate debt market is still at an embryonic stage. Although corporate deposits have long been a popular investment avenue for retail investors, there is less interest in corporate bonds suggesting that retail investors may be more comfortable with credit risk than with market (interest rate) risk. Furthermore, the secondary market has suffered from a lack of market making resulting in poor liquidity in most maturities. The concentration of turnover suggests that investors' appetite is mainly for highly rated instruments, with more than $80 \%$ of secondary market turnover in AAA-rated securities (Sharma and Sinha, 2006). Therefore, we use yields on AAA-rated corporate bonds for the same maturities as before to construct the level, slope and curvature of the corporate yield curve.

\footnotetext{
${ }^{10}$ These are weighted averages of yields on all bonds of the corresponding maturity being traded in the corresponding month with the volumes as weights and yields computed on a zero coupon basis (RBI, 2007).
} 
Finally, we calculate the risk premiums for 1-year, 5-year and 10-year maturities as the difference between the corporate bond yield and the government bond yield in the corresponding maturities. Based on the risk premiums, we construct the level, slope and curvature of the credit spread yield curve. The macroeconomic and government bond data are sourced from the RBI while the corporate bond data are obtained from Bloomberg. We use monthly data from December 2001 to December 2010, ${ }^{11}$ the choice being constrained by the earliest availability of data on corporate bonds.

The descriptive statistics of the term structure factors for the government and corporate yield curves are presented in Table 1. Columns 2-4 of the table refer to the government yield curve's level (GLEVEL), slope (GSLOPE) and curvature (GCURVATURE) while the next three columns pertain to the corporate yield curve's level (CLEVEL), slope (CSLOPE) and curvature (CCURVATURE). The mean values suggest that average term spread (indicated by the slope) in India is around $1 \%$ which compares well with international standards. The average credit spread (difference between the levels of the corporate and government yield curves) is also around $1 \%$. The negative curvatures imply that the yield curves have concave shapes. Average yields have low skewness and moderate kurtosis which suggests that levels of the two yield curves are normally distributed (both the Jarque-Bera and Shapiro-Wilk tests of normality do not reject the null of normality at 5\% levels of significance). The slopes and curvatures are, however, nonnormal.

\section{Empirical Results}

The empirical exercise proceeds in the following steps. First, we present the PCI and study its properties and appropriateness in being representative of monetary policy decisions. Second, we

\footnotetext{
${ }^{11}$ Since May 2011, RBI shifted to a new operating procedure of monetary policy whereby the repo rate became the sole independently varying policy rate while the newly constituted marginal standing facility and the reverse repo rate are pegged at 100 basis points above and below the repo rate, respectively. As our principal component measure is based on discrete and independent changes in repo, reverse repo and CRR, we have restricted our analysis to 2010 in order to avoid inconsistency in PCI measure across periods.
} 
study the impact of monetary policy on the shape of the government bond yield curve using the PCI. Third, we examine the impact of monetary policy, as represented by the PCI, on the shape of the corporate bond yield curve. Fourth, we look at policy impact on the credit spread yield curve. Finally, we examine how the three yield curves affect monetary policy.

\subsection{Performance of the monetary policy index}

We begin the discussion with the results of the principal components analysis which are presented in Table 2 . The first principal component $\left(1^{\text {st }} \mathrm{PC}\right)$ appears to explain $73 \%$ of the variation in the data (Table 2 - Panel A). The Eigen vectors suggest that the weights of all three instruments are positive only in the $1^{\text {st }} \mathrm{PC}$ (Table 2 - Panel B); hence, we use this as our index of monetary policy and refer to it as PCI. The relative importance of the repo rate is the highest followed by the reverse repo rate and the cash reserve ratio in the PCI, which would imply that the repo rate is the most active among the policy instruments. ${ }^{12}$

From the descriptive statistics of the PCI (see Table 1), we observe that the index takes zero value on an average over the sample period. This suggests that contractionary and expansionary policies had roughly equal strengths during the period of study. In other words, there has been no systematic bias in policy decisions despite multiple objectives of policy. The null hypothesis is not rejected by both the Jarque-Bera and Shapiro-Wilk tests which indicate that the PCI is normally distributed. The PCI is plotted in Figure 1. It can be observed that the PCI takes higher (lower) score during periods of monetary tightening (easing) i.e., when any or a combination of the three instruments increase (decrease). Of the period of study spanning 109 months, monetary policy has been contractionary on 23 occasions whereas it has been expansionary on 15 occasions as per our proposed measure. While the expansionary phases are concentrated in the period after the unravelling of the IT bubble in the US in the early part of the decade and during the peak of

\footnotetext{
12 Recent empirical evidence on the operating procedure of monetary policy in India suggests that monetary transmission is stronger in deficit liquidity conditions; hence the repo rate is the key policy rate (RBI, 2011).
} 
the global financial crisis, contractionary episodes are more distributed reflecting measures to prevent the overheating of the economy during the decade (in which the economy has experienced sustained high growth) but concentrated particularly in the last year of the sample period when policy was tightened to curb intensifying inflation pressures in the wake of rising global food and commodity prices.

How does the proposed PCI relate to some key financial market indicators? We checked the relationship of the PCI with the call money rate (CMR), the 91-day treasury bill rate (TB91) and the spread between the commercial paper rate and the treasury bill rate (SPREAD), which have often been used as proxies for monetary policy in the empirical literature (Kashyap et al., 1993; Boschen and Mills, 1995). Bivariate Vector Auto Regressions (VAR) with PCI and each money market variable revealed that changes in PCI lead to statistically significant responses in CMR, TB91 and SPREAD (see Granger causality test results in Table 3). Figure 2 shows the impulse responses along with bootstrapped standard error bands at $95 \%$ confidence levels. The dotted bands follow the confidence intervals of Efron and Tibshirani (1993) while the shaded bands follow the confidence intervals due to Hall (1992). Both are calculated based on the lower and upper quantiles of the estimated bootstrapped impulse response coefficients. However, Hall (1992) differs from Efron and Tibshirani (1993) in his use of Edgeworth expansion approximation rather than resampling. We prefer to use bootstrap confidence intervals to those based on asymptotic theory as the former are known to be more reliable and can mitigate sampling uncertainty such as those due to generated regressors like our PCI variable (Adrian and Moench, 2008).

Our impulse response analysis showed that a shock in the PCI leads to a positive and significant response in CMR and TB91 up to 10 months. The response of SPREAD is also positive but statistically significant up to 6 months. Overall, the findings suggest that the PCI is adequately representative of monetary policy actions. 


\subsection{Impact of monetary policy on the government yield curve}

We discuss the results of the SVAR model through the impulse response analysis and the forecast error variance decomposition. The impulse responses are presented in Panel A of Figure 3. The first graph shows the response of the level of the government yield curve to a shock in the PCI. From the graph, it can be noted that the impact of monetary policy on the level of the government yield curve is positive and statistically significant up to 3 months, suggesting that policy tightening results in an increase in average yields which persists for about 3 months. Policy tightening is perceived to reflect higher inflation concerns in the short-term, therefore it shifts the yield curve upwards temporarily as commonly found in the literature (e.g., Evans and Marshall; 1998, 2007).

The next graph in Figure 3.A shows the response of the slope of the government yield curve to a shock in the PCI. The impact on the slope is negative and statistically significant up to 11 months. This suggests a flattening of the yield curve in response to monetary policy tightening. This result is consistent with the findings in the US (Diebold et al., 2006) and some emerging markets (Drakos, 2001) ${ }^{13}$ suggesting that long rates react sluggishly to monetary policy. Our findings in the Indian context suggest the dominance of the expectations hypothesis over risk premia considerations in the short term resulting in a higher impact of policy at the short end..${ }^{14}$ However, other factors, such as portfolio readjustments through a flight to quality (greater demand for 10year paper) or global economic or currency situations may also result in an increase in demand for long-term bonds with consequent decline in yields.

\footnotetext{
${ }^{13}$ Drakos (2001) found that while monetary policy actions do exert an impact on the entire term structure in the Greek money market, the magnitude of the effect decreases monotonically with higher maturity.

${ }^{14}$ In the finance literature, the pure expectations hypothesis assumes that all changes in yield curve steepness reflect the market's shifting rate expectations, while the risk premium hypothesis assumes that the changes in steepness only reflect changing bond risk premia. In reality, both rate expectations and required risk premia influence the curve's slope (Wets and Bianchi, 2006). Taboga (2009), however, cautions that more than the risk premia, it is the reduction in key variables such as the real natural rate of interest, inflation expectations and growth rate of potential output that may have contributed to a fall in long-term bond yields both in the US and in the euro area in recent years.
} 
Finally, the last graph in Figure 3.A shows the response of curvature of the government yield curve to a shock in the PCI. The graph shows that the impact on curvature is positive and statistically significant up to 11 months. In other words, the impact on the 5-year yields is not as strong as the impact on the short and long end of the yield curve implying that the yield curve becomes more convex (less 'hump-shaped') in response to monetary policy tightening. ${ }^{15}$ The change in curvature also reflects shifting market perceptions about yield curve dynamics where expectations of yields of the short and long term dominate that of the medium term (Giese, 2008). Moreover, it could also reflect the relatively less liquid nature of 5-year bonds vis-a-vis those of 1 and 10-year maturities.

We cross-checked the above results (and all subsequent ones) for level, slope and curvature by considering the individual yields in the SVAR in place of the underlying factors of the yield curve. The results turned out to be consistent in each case but are not reported here.

To complement the impulse response analysis, we present the forecast error variance decomposition in Table 4. In case of all three factors, monetary policy shocks (measured by the PCI) seem to be the dominant influence in explaining variance. This is in line with the impulse response results discussed above but in contrast to the US where inflation was found to be the dominant factor in explaining the level of the yield curve (Bekaert et al., 2010). However, it is interesting to observe from our variance decomposition results that the relative impact of monetary policy on the level of the yield curve decreases beyond the six-month horizon while IIP starts playing a fairly significant role. This result suggests that once the beneficial impact of monetary policy actions in terms of stable inflation expectations are factored in by market participants, real economic activity plays an important role in determining yields across maturities. ${ }^{16}$

\footnotetext{
15 The market's curve reshaping expectations, volatility expectations and expected return structure determine the curvature of the yield curve. Expectations for yield curve steepening or for low volatility along with low required returns on intermediate bonds can make the yield curve convex (Wets and Bianchi, 2006).

${ }^{16}$ At the same time, yield spread is found to be a leading indicator of economic activity explaining about $40 \%$ of the variation in future growth of industrial output in India (Kanagasabapathy and Goyal, 2002).
} 


\subsection{Impact of monetary policy on the corporate yield curve}

We report the results of the impulse response analysis for the impact of monetary policy on the corporate yield curve in Panel A of Figure 4. From the first graph, it is noted that the impact on the level is positive and statistically significant up to 8 months suggesting that monetary policy tightening results in an increase in average corporate yields and the effect persists till 8 months.

The next graph in Figure 4.A shows the response of the slope of the corporate yield curve to a shock in the PCI suggesting that the impact on the slope is negative and statistically significant up to 9 months. Similar to the case of the government yield curve, this suggests a flattening of the corporate yield curve in response to monetary policy tightening.

Finally, the last graph in Figure 4.A shows the response of curvature of the corporate yield curve to a shock in the PCI. The impact on curvature is positive and statistically significant up to 9 months. In other words, the impact on the 5-year yields is not as strong as the impact on the short and long end of the yield curve i.e., the yield curve becomes more convex in response to monetary policy tightening as in the case of government bonds. The similarities of these results with those for government bonds imply that government bonds are a reliable benchmark for the pricing of corporate paper.

Once again, we present the forecast error variance decomposition results to complement the above findings. The results in Table 5 suggest that monetary policy starts playing a dominant role in explaining the variance of level, slope and curvature from six months onwards as against one month in the government bond market. Thus, while monetary policy has a more instantaneous impact on the government bond market, it has a delayed impact on the corporate bond market. The corporate bond market is thin as compared to the government bond market as it has far lesser issuances than government paper. Moreover, unlike government bonds where all resources are raised from the domestic market, corporate entities have the advantage of mobilising resources 
from other sources such as external commercial borrowing, which is often accessed during periods of low international interest rates, favourable exchange rates and heightened domestic uncertainty.

\subsection{Impact of monetary policy on the credit spread yield curve}

Next, we consider the impact of monetary policy on the yield curve of credit spreads. The results of the impulse response analysis are presented in Panel A of Figure 5. We find that the response of the level of the credit spread yield curve to shocks in the PCI is positive and statistically significant beyond 4 months and up to 10 months. This suggests that the differential impact of monetary policy tightening on corporate risk is stronger over the medium term implying that market participants adjust to policy tightening gradually by raising the risk premia. In case of the impulse responses of the slope and curvature to monetary policy shocks, we find that the standard error bands straddle the zero-axis which suggests that the responses are not significant.

\subsection{Impact of yield curves on monetary policy}

Finally, we consider the response of monetary policy to shocks in the slope, level and curvature of the government and corporate yield curves. Moench (2012) points out that the evidence for the predictive content of individual components of the yield curve is limited. We go back to the models estimated in sections 5.2-5.4 and discuss here the impulse responses for the impact of the yield curve factors on monetary policy. The results are presented in Panel B of Figure 3. We find that the response of PCI to shocks in the level of the government yield curve is positive and statistically significant beyond 3 months. This implies that either the bond market anticipates changes in monetary policy 3 months ahead or that monetary policy responds to shifting yield levels with a lag of 3 months which is somewhat similar to the evidence from the US (Diebold et al., 2006). An increase in bond yields might be indicative of expected inflationary pressures in the near future which the central bank then tries to address through policy tightening. However, there seems to be no significant impact of the slope and curvature of the government yield curve on monetary policy. 
Moving to the corporate yield curve, Panel B of Figure 4 suggests that its level, slope and curvature do not have a statistically significant impact on monetary policy. In case of the credit spread yield curve, however, Panel B of Figure 5 reveals that the level has a statistically significant impact on monetary policy between 1 and 6 months. This result implies that the central bank responds to heightened risk premia through expansionary measures that reduces the default risk in the economy.

\subsection{Robustness check}

\subsubsection{Narrative Based Index}

In order to assess the robustness of our results, we carried out two sets of exercises. In the first case, we re-estimated our models but this time with a different monetary policy index. In empirical research on monetary policy, Romer and Romer (1989) pioneered the 'narrative approach' wherein federal open market committee (FOMC) directives and related records in the US were utilised and interpreted to identify the stance of monetary policy. A logical extension of the basic narrative approach was the construction of a monetary policy index by Brunner and Meltzer (1989) and later by Boschen and Mills (1991; 1995). The index depicts a mapping of the qualitative discussions in policy records to a quantitative scale by assigning a number indicating the degree of easing or tightening of policy. To test the robustness of our previous findings that used the PCI, we generate a narrative based measure in the Indian context and refer to it as the Narrative Based Index (NBI). There is, however, a difference between the Boschen-Mills Index (BMI) and the NBI. While BMI derives the measure by interpreting the intent of policy from FOMC statements, the NBI is a quantification of the actual measures undertaken by the RBI. While interpretations of policy stance from official documents may suffer from subjectivity bias of market participants, actual measures are free of any interpretation errors.

We constructed the NBI by mapping the policy measures undertaken during the period of study to pre-defined scores. NBI is a monthly incremental measure, which represents whether there has 
been any change in monetary policy from the previous month. While hikes in policy instruments indicate contractionary policy, reductions are expansionary. ${ }^{17}$ First, all the three instruments are listed on a monthly basis as percentage changes from their previous month's values. Second, such changes in all three instruments are aggregated on a monthly basis. Next, the sum of all changes are categorised in terms of their magnitudes viz., (0-10)\%, (10-20)\%, and more than 20\%; which are given scores of 1,2 , and 3 , respectively for positive changes indicating the extent of policy tightening. Similarly, $-1,-2$ and -3 are accorded for negative changes indicating policy easing. ${ }^{18}$ Therefore, the mapping of policy measures generates seven scores, ranging from -3 to 3 with 0 being assigned to neutral policy which can occur due to policy inaction in any period.

We re-estimated all the models presented earlier with the NBI replacing the PCI. The results are not reported here to save space but are available with the authors. Our basic findings on the impact of monetary policy on the shape of the government as well as corporate yield curves are identical when monetary policy is measured by the NBI thereby suggesting robustness of the earlier findings. However, while the PCI provides evidence of increasing credit spreads from policy tightening, the NBI does not suggest any statistically significant impact. Thus, the PCI performs better vis-a-vis the NBI in capturing the response of risk premia to monetary policy actions. The earlier results for the response of monetary policy to shocks in the yield curve also hold when monetary policy is measured with the NBI with one exception. While the PCI responded significantly to shocks in the level of the government yield curve, there is no such significant response in case of the NBI.

\subsubsection{Generalised Impulse Response Functions}

\footnotetext{
${ }^{17}$ A positive monetary policy shock is contractionary in our study in contrast to BMI, where such shocks are interpreted as expansionary policy.

${ }^{18}$ A value of 3 is indicative of strong contractionary, 2 is contractionary and 1 is mild contractionary policy while a value of -1 represents mild expansionary, -2 reflects expansionary and -3 represents strong expansionary policy.
} 
In the second robustness check, we used the PCI as our monetary policy index but implemented a different identification scheme than the one described in Section 3. The structural VAR that was used earlier and the more common Cholesky identification scheme are often criticized for imposing a particular ordering of the variables. In order to ensure that our results are invariant to the ordering of the variables, we calculated the generalized impulse response functions for the models estimated earlier. The results are not reported to save space but are available with the authors. Our previous findings for the impact of monetary policy on the yield curve remain qualitatively unchanged despite the change in identification scheme. The government yield curve shows a statistically significant response to shocks in the PCI although the impact on the level now persists for a longer period i.e., up to 7 months. The impact of the PCI on the slope and curvature persist till about a year as before. In case of the corporate yield curve, we find that the impact of the PCI on the slope, level and curvature are all statistically significant up to a year. The responses of the level of the credit spread yield curve to monetary policy shocks are statistically insignificant as found earlier. Moving to the impact of shocks to the yield curve on monetary policy we find that the level, slope as well as curvature of the government yield curve have a significant impact on the PCI. This is in contrast with our previous finding where only the level of the government yield curve had a significant effect on the PCI. However in line with our previous findings, the shape of the corporate yield curve does not have any statistically significant effect on monetary policy. Finally, the level of the credit spread yield curve has a negative and statistically significant impact on the PCI indicating that the central bank implements expansionary monetary policy in response to enhanced risk premia. This is similar to our previous result based on the SVAR. The effects of the slope and curvature of the credit spread yield curve on the PCI are statistically insignificant - similar to what was reported earlier.

\subsection{Implications of findings}


The similar pattern of response of the government bond and corporate yield curve to monetary policy raises several interesting points. First, the significant response of the level of the yield curve to policy changes is indicative of the market's reaction even as government borrowings have been consistently higher in the wake of chronic fiscal deficits. Large fiscal deficits tend to have a negative impact on market sentiment about liquidity conditions, harden inflation expectations and, consequently, exert upward pressure on yields. Second, the negative impact on slope is a pointer to the immediate reaction of market participants in the short-term. Third, the positive impact of policy tightening on curvature - showing greater impact on short and long term rates relative to medium term - may be indicative of the market's volatility expectations and expected return being more biased towards short and long term vis-a-vis medium term bonds indicating market segmentation.

The predominance of monetary policy among macroeconomic factors in explaining the shape of the yield curve suggests that given the persistence of large market borrowing programme over the years, the Indian bond market remains substantially responsive to policy signals. Therefore, the RBI has an important role in furthering market development by guiding expectations. This would also facilitate the development of a robust pricing mechanism for other segments of the financial market in India, given the reliability of government bond yields as an appropriate benchmark. Finally, the significant response of monetary policy to shocks in the term structure of government bonds can be explained on two counts. While this result implies that bond yields contain information about future policy changes, it also suggests that the monetary authority takes cognizance of developments in the bond market as an information variable in policy formulation. While the corporate yield curve does not have a significant impact on monetary policy, the response of monetary policy to shocks in the credit spread yield curve suggest that the monetary authority is concerned about heightened risk perception and reacts through expansionary policy.

\section{Conclusion}


This paper adopts a macro-finance approach in analysing the impact of monetary policy on the bond market yield curve of an emerging economy viz., India. In this regard, the paper contributes in an area which has, hitherto, received relatively less attention in the literature. The paper enriches the understanding of monetary policy and market dynamics of the bond market in India on two counts. First, it proposes and develops a summative measure of monetary policy to account for the multiple instruments employed by the central bank and uses it to assess the impact on the yield curve. Second, it examines the impact on the government yield curve, the corporate yield curve and the credit spread yield curve in terms of the latent factors using market proxies.

The empirical exercise demonstrates that while monetary policy impacts the entire term structure in terms of level, it alters the slope by having a stronger impact at the shorter end, which results in a flattening of the yield curve. Moreover, the higher impact on the short and long end vis-à-vis the medium term implies greater convexity of the yield curve which is reflective of the market bias on expected return from preferred segments of maturities. Furthermore, monetary policy tightening has a significant impact on credit spreads over the medium term implying that the market demands greater risk premia during policy tightening thereby indicating a distinct preference for safe assets. ${ }^{19}$ Thus, given the persistence of chronic fiscal deficits and the RBI's dual role as the monetary authority and the debt manager, the results show that the bond market is responsive to policy signals from the central bank. These findings throw some insights on the modus operandi of further developing the Indian bond market.

Our findings are markedly different from the existing literature on India based on a clear methodological distinction. For instance, while Sahoo and Bhattacharyya (2012) include the proxies for level, slope, and curvature one by one while estimating the SVAR, we include all three at the same time which is more credible as it allows for the assessment of an impact of monetary

\footnotetext{
19 This is particularly true for banks as they try to hold more of government bonds not only from a risk-return perspective but also because greater holding of risk-free assets entails lower provisioning for capital adequacy.
} 
policy on level, slope, and curvature simultaneously. As a result, there are a couple of stark differences in our findings with that of Sahoo and Bhattacharyya (2012). First, monetary policy tightening, according to us, has a greater impact on short and long term yields in contrast to medium term. Second, we report the dominance of monetary policy in explaining the slope of the yield curve (as reported by Bekaert et al., 2010 for the US) as against exchange rate found in Sahoo and Bhattacharyya (2012).

The measures of monetary policy introduced in the paper is particularly important in the context of emerging market economies (EMEs), who often pursues multiple monetary policy objectives and operates through both rate and quantum channels for effective policy transmission. Although both measures give similar results, the absence of 'subjectivity bias' and superior diagnostics of the PCI vis-a-vis the NBI makes it an appropriate representation of monetary policy stance. Moreover, it is able to reflect the response of credit spreads to monetary tightening unlike the NBI. These features of the PCI suggest that it can be effectively used to assess financial market response in EMEs. As the institutional features in these economies become extremely important for financial markets to develop, deeper analysis of the policy objectives and the operating procedure of monetary policy is an important prerequisite for understanding the complexities and challenges facing market development in EMEs. This paper hopes to trigger more intensive research in this direction. 


\section{References}

1. Adrian, T., Moench, E., 2008. Pricing the term structure with linear regressions. Staff Reports 340, Federal Reserve Bank of New York.

2. Amisano, G., Giannini, C., 1997. Topics in Structural VAR Econometrics, 2nd edition, Springer: Berlin.

3. Ang, A., Piazzesi, M., 2003. A no-arbitrage vector autoregression of term structure dynamics with macroeconomic and latent variables. Journal of Monetary Economics 50, 745-787.

4. Bahmani-Oskooee, M., Mitra, R., 2010. How sensitive is commodity trade flows between US and India to currency depreciation? Applied Economics 42, 267-277.

5. Bekaert, G. Cho, S., Moreno, A., 2010. New Keynesian Macroeconomics and the Term Structure. Journal of Money, Credit and Banking 42, 33-62.

6. Bhattacharyya, I., Sensarma, R., 2008. How Effective are Monetary Policy Signals in India? Journal of Policy Modelling 30(1), 169-183.

7. Boschen, J.F., Mills, L.O., 1991. The Effects of Countercyclical Monetary Policy on Money and Interest Rates: An Evaluation of the Evidence from FOMC documents. Federal Reserve Bank of Philladelphia Working Paper No. 91-20.

8. Boschen, J.F., Mills, L.O., 1995. The Relation between Narrative and Money Market Indicators of Monetary Policy. Economic Inquiry 33, 24-44.

9. Brunner, K., Meltzer, A.H., 1989. The Federal Reserve's Attachment to the Free Reserve Concept, Reprinted in Karl Brunner and Allan H Meltzer (Eds.), Monetary Economics. Basil Blackwell: Oxford.

10. Burdekin, R.C.K., Siklos, P.L., 2008. What has driven Chinese monetary policy since 1990? Investigating the People's bank's policy rule. Journal of International Money and Finance 27(5), 847-859.

11. Dai, Q., Singleton, K.J., 2000. Specification Analysis of Affine Term Structure Models. Journal of Finance 55, 531-52.

12. Doan T. A. (2000). Rats, User's Guide. Estima, Evanston, IL

13. Diebold, F.X., Piazzesi, M., Rudebusch, G.D., 2005. Modelling bond yields in finance and macroeconomics. American Economic Review 95, 415-20.

14. Diebold, F.X., Rudebusch, G.D., Aruoba, S.B., 2006. The macroeconomy and the yield curve: a dynamic latent factor approach. Journal of Econometrics 131, 309338. 
15. Drakos, K., 2001. Monetary policy and the yield curve in an emerging market: the Greek case. Emerging Markets Review 2, 244-262.

16. Efron, B., Tibshirani, R.J., 1993. An Introduction to the Bootstrap. Chapman \& Hall: New York.

17. Evans, C.L., Marshall, D.A., 1998. Monetary policy and the term structure of nominal interest rates: evidence and theory. Carnegie-Rochester Conference on Public Policy 49, 53-111.

18. Evans, C.L., Marshall, D.A., 2007. Economic Determinants of the Nominal Treasury Yield Curve, Journal of Monetary Economics 54, 1986-2003.

19. Giese, J.V., 2008. Level, Slope, Curvature: Characterising the Yield Curve in a Cointegrated VAR Model. Economics - The Open-Access E-Journal 2(28), 1-20.

20. Glocker,C., Towbin, P., 2012. Reserve Requirements for Price and Financial Stability: When Are They Effective?, International Journal of Central Banking, $8(1), 65-113$.

21. Hall, P., 1992. The Bootstrap and Edgeworth Expansion. Springer: New York.

22. Kanagasabapathy, K., Goyal, R., 2002. Yield Spread as a Leading Indicator of Real Economic Activity: An Empirical Exercise on the Indian Economy, IMF Working Paper, WP/02/91.

23. Kanjilal, K. (2011): "Macroeconomic Factors and Yield Curve for Emerging Indian Economy", Macroeconomics and Finance in Emerging Market Economies 4(1), 5783.

24. Kanjilal, K. (2013): "Factors causing Movements of Yield Curve in India", Economic Modelling 32, 100-107.

25. Kashyap, A.K., Stein, J.C., Wilcox, D.W., 1993. Monetary policy and credit conditions: evidence from the composition of external finance. American Economic Review 83(1), 78-98.

26. Knez, P.J. Litterman, R., Scheinkman, J.A., 1994. Explorations into Factors Explaining Money Market Returns. Journal of Finance 49, 1861-82.

27. Moench, E., 2012. Term structure surprises: the predictive content of curvature, level, and slope. Journal of Applied Econometrics 27(4), 574-602.

28. Montoro, C., Moreno, R., 2011. The use of reserve requirements as a policy instrument in Latin America. BIS Quarterly Review, March, 53-65. 
29. Musard-Gies, M., 2006. Do European Central Bank's Statements Steer Interest Rates In The Euro Zone? Manchester School 74(s1), 116-139.

30. Pesaran, M. H., Shin, Y., 1998. Generalized Impulse Response Analysis in Linear Multivariate Models. Economics Letters 58, 17-29.

31. Reserve Bank of India, 2011. Report of the Working Group on Operating Procedure of Monetary Policy.

32. Romer, C., Romer, D. H., 1989. Does Monetary Policy Matter? A New Test in the Spirit of Friedman and Schwartz. In: Blanchard, O. J., Fischer, S. (Eds.), NBER Macroeconomics Annual, 121-69.

33. Rudebusch, G. D., Wu, T., 2008. A Macro-Finance Model of the Term Structure, Monetary Policy, and the Economy. Economic Journal 118, 906-26.

34. Sahoo, B. K., Acharya, D., 2010. An Alternative Approach to Monetary Aggregation in DEA. European Journal of Operational Research 204, 672-682.

35. Sahoo, S. and Bhattacharyya, I. (2012): "Yield Curve Dynamics of the Indian GSec Market: A Macro-Finance Approach", Indian Economic Review, Vol. XLVII, No. 2.

36. Sharma, V. K., Sinha, C., 2006. The corporate debt market in India. In: BIS (Eds.), Developing Corporate Bond Markets in Asia, BIS Paper No. 26, 80-87.

37. Sims, C. A., 1980. Macroeconomics and Reality. Econometrica 48 (10), 1-48.

38. Sims, C. A., Stock, J. H., Watson, M.W., 1990. Inference in Linear Time-Series Models with Some Unit Roots. Econometrica 58(1), 113-144.

39. Taboga, M., 2009. Macro-finance VARs and bond-risk premia: A caveat. Review of Financial Economics 18(4), 163-171.

40. Wets, R. J. B., Bianchi, S. W., 2006. Term and Volatility Structures. In Zenios, S. A., Ziemba, W. T., (Eds.) Handbook of Asset and Liability Management, Volume 1. North-Holland. 
Table 1: Descriptive Statistics of Yield Curve Factors and Principal Components Index

\begin{tabular}{lccccccc}
\hline Statistic & GLEVEL & GSLOPE & GCURVATURE & CLEVEL & CSLOPE & CCURVATURE & PCI \\
\hline $\begin{array}{l}\text { Mean } \\
\text { Standard }\end{array}$ & 6.686 & 1.025 & -0.417 & 7.838 & 0.982 & -0.404 & 0.000 \\
Deviation & 1.005 & 0.776 & 0.653 & 1.478 & 0.889 & 0.767 & 1.470 \\
Skewness & 0.004 & 0.840 & -1.291 & 0.240 & 0.544 & -0.988 & 0.163 \\
Kurtosis & 2.668 & 3.271 & 3.756 & 2.612 & 3.643 & 3.581 & -0.611 \\
Jarque-Bera & & & & & & & \\
test & 0.502 & 13.161 & 32.850 & 1.727 & 7.245 & 19.261 & 2.319 \\
P-value & 0.778 & 0.001 & 0.000 & 0.422 & 0.027 & 0.000 & 0.314 \\
Shapiro-Wilk & & & & & & & \\
test & 1.538 & 4.120 & 5.854 & 1.525 & 2.777 & 4.161 & 1.090 \\
P-value & 0.062 & 0.000 & 0.000 & 0.064 & 0.003 & 0.000 & 0.138 \\
Observations & 109 & 109 & 109 & 109 & 109 & 109 & 109 \\
\hline
\end{tabular}

Note: This table presents some descriptive statistics for the government yield curve's level (GLEVEL), slope (GSLOPE), curvature (GCURVATURE); the corporate yield curve's level (CLEVEL), slope (CSLOPE), curvature (CCURVATURE); and the monetary policy index (PCI).

Table 2: Principal component analysis

Panel A

\begin{tabular}{llc}
\hline $\begin{array}{l}\text { Principal } \\
\text { Component } \\
\text { (PC) }\end{array}$ & $\begin{array}{l}\text { Eigen value (indicates } \\
\text { the variation in the data } \\
\text { explained by each } \\
\text { principal component) }\end{array}$ & $\begin{array}{l}\text { Proportion of } \\
\text { variance explained } \\
\text { by each principal } \\
\text { component }\end{array}$ \\
\hline $\mathbf{1}^{\text {st }} \mathbf{P C}$ & 2.182 & 0.727 \\
$\mathbf{2}^{\text {nd }} \mathbf{P C}$ & 0.726 & 0.242 \\
$\mathbf{3}^{\text {rd }} \mathbf{P C}$ & 0.093 & 0.031 \\
\hline
\end{tabular}

Eigenvectors (indicate the weight coefficient of each variable in the principal component)

\begin{tabular}{lccc}
\hline Variable & $\mathbf{1}^{\text {st }} \mathbf{P C}$ & $\mathbf{2}^{\text {nd }} \mathbf{P C}$ & $\mathbf{3}^{\text {rd }} \mathbf{P C}$ \\
Cash Reserve Ratio & 0.436 & 0.897 & 0.066 \\
Repo rate & 0.643 & -0.260 & -0.720 \\
Reverse Repo rate & 0.629 & -0.356 & 0.691 \\
\hline
\end{tabular}

Note: This table presents results from a principal component analysis of the three monetary policy instruments (Cash Reserve Ratio, Repo rate and Reverse Repo rate).

Table 3: Monetary policy index and key money market variables - Granger causality

\begin{tabular}{lrr}
\hline Null hypothesis & Test statistic & P-value \\
\hline PCI does not Granger-cause CMR & 11.392 & 0.000 \\
PCI does not Granger-cause TB91 & 8.059 & 0.000 \\
PCI does not Granger-cause SPREAD & 4.270 & 0.015 \\
\hline
\end{tabular}

Note: This table presents Granger causality results from bivariate vector auto regressions involving the monetary policy index (PCI) and one money market variable viz. call money rate (CMR), 91-day treasury bill rate (TB91) or spread of treasury bill rate over commercial paper rate (SPREAD). 
Figure 1: PCI and monetary policy instruments

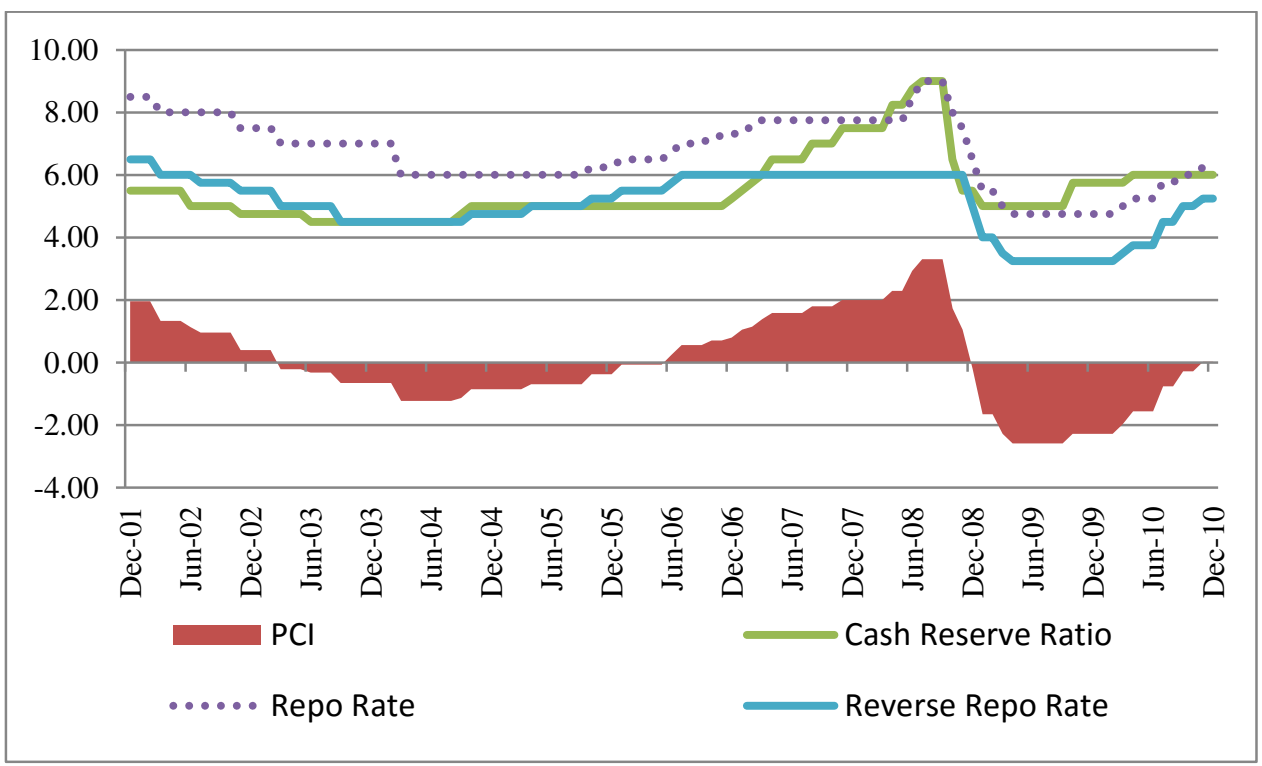

Note: This graph plots the values of the three monetary policy instruments (Cash Reserve Ratio, Repo Rate and Reverse Repo Rate) and the monetary policy index (PCI).

Figure 2: Monetary policy and money market variables - impulse responses

Response of CMR, TB91 and SPREAD to shocks in PCI
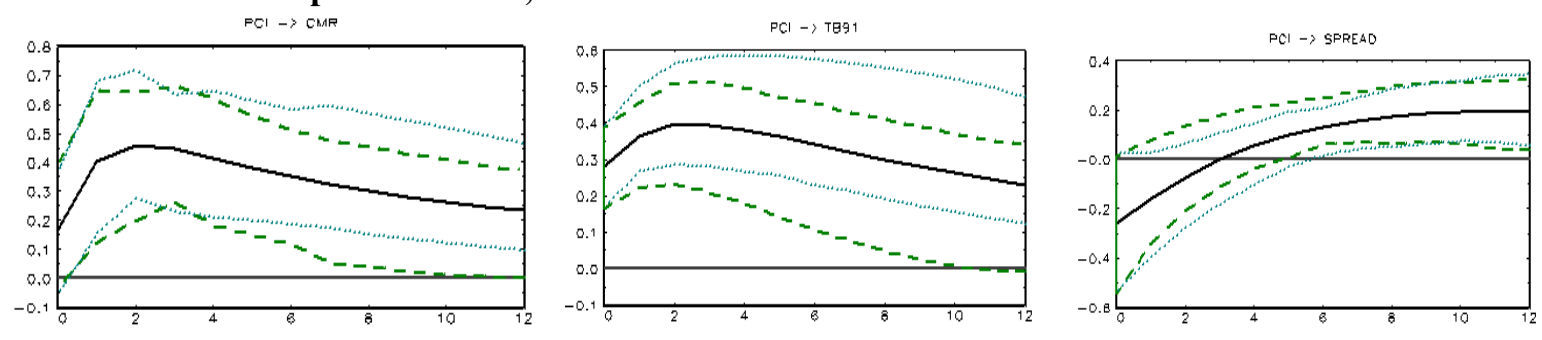

Note: These graphs show the impulse responses of call money rate (CMR), 91-day treasury bill rate (TB91) and spread of treasury bill rate over commercial paper rate (SPREAD) to innovations in the monetary policy index (PCI). The bold lines are the impulse responses. The dotted and dashed lines are standard error bands (following Effron and Tibshirani, 1993 and Hall, 1992, respectively). 
Figure 3: Monetary policy and the government yield curve - impulse responses

Panel A - Response of GLEVEL, GSLOPE and GCURVATURE to shocks in PCI

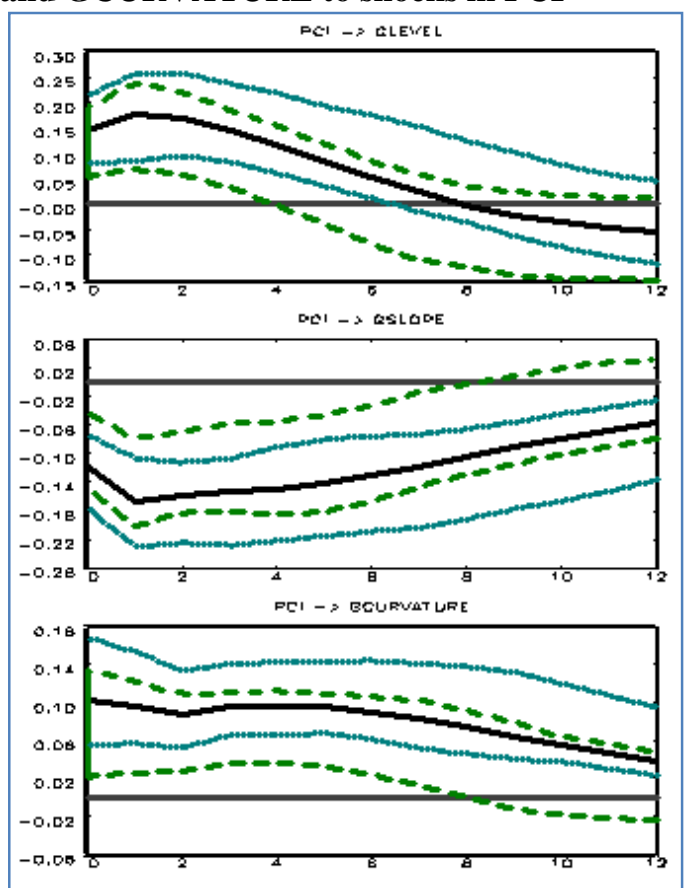

Panel B - Response of PCI to shocks in GLEVEL, GSLOPE and GCURVATURE

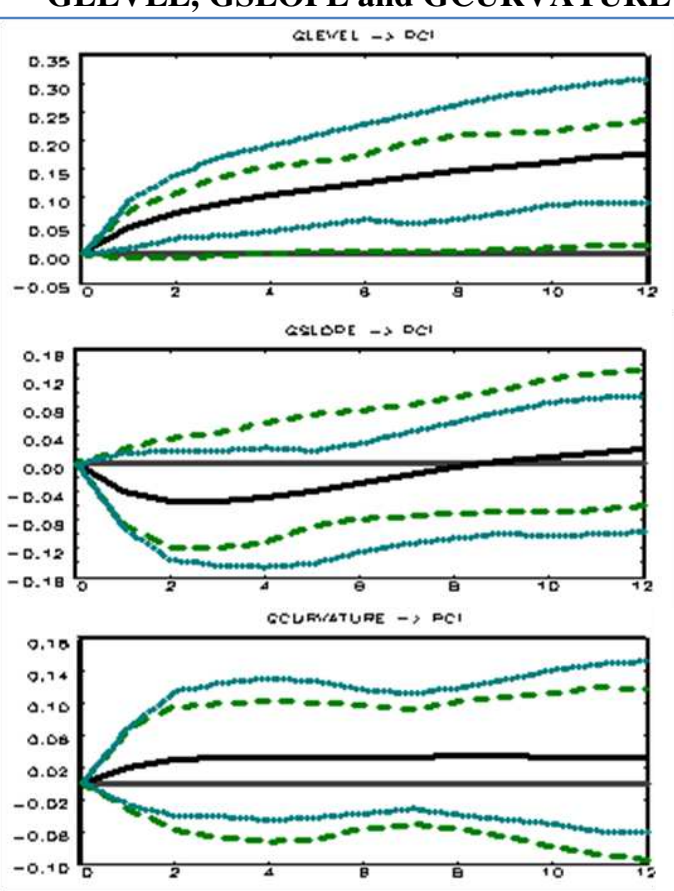

Note: These graphs show the dynamic interactions between the government yield curve's level (GLEVEL), slope (GSLOPE), curvature (GCURVATURE) and monetary policy (PCI). The bold lines are the impulse responses. The dotted and dashed lines are standard error bands (following Effron and Tibshirani, 1993 and Hall, 1992, respectively).

Figure 4: Monetary policy and the corporate yield curve - impulse responses

Panel A - Response of CLEVEL, CSLOPE and CCURVATURE to shocks in PCI

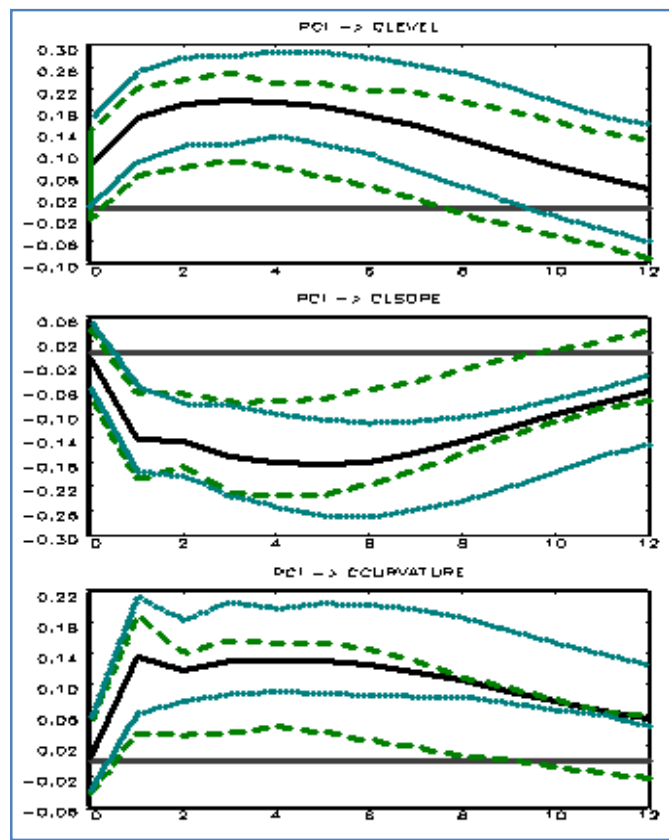

Panel B - Response of PCI to shocks in CLEVEL, CSLOPE and CCURVATURE
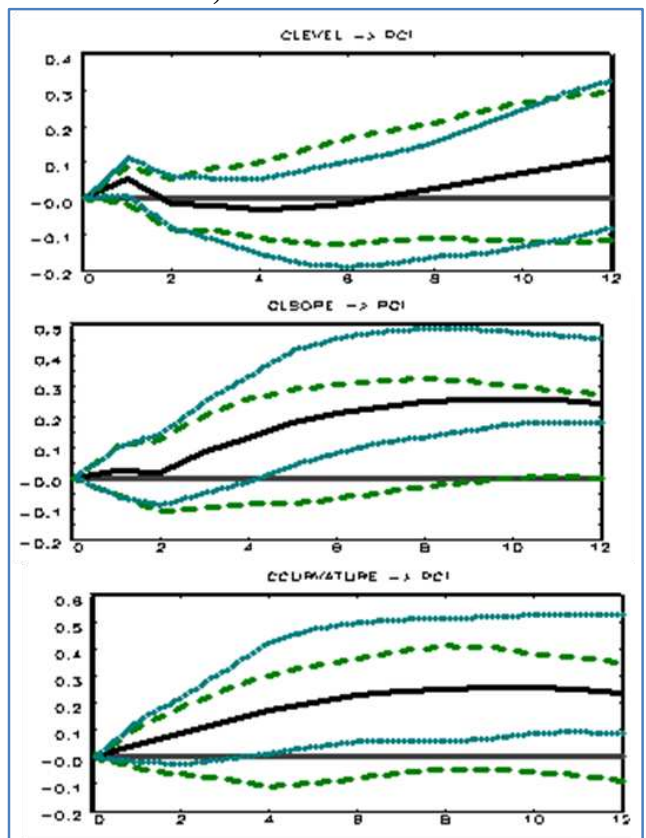

Note: These graphs show the dynamic interactions between the corporate yield curve's level (CLEVEL), slope (CSLOPE) and curvature (CCURVATURE) and monetary policy (PCI). The bold lines are the impulse responses. The dotted and dashed lines are standard error bands (following Effron and Tibshirani, 1993 and Hall, 1992, respectively). 
Figure 5: Monetary policy and the credit spread yield curve - impulse responses

Panel A - Response of RLEVEL, RSLOPE and RCURVATURE to shocks in PCI

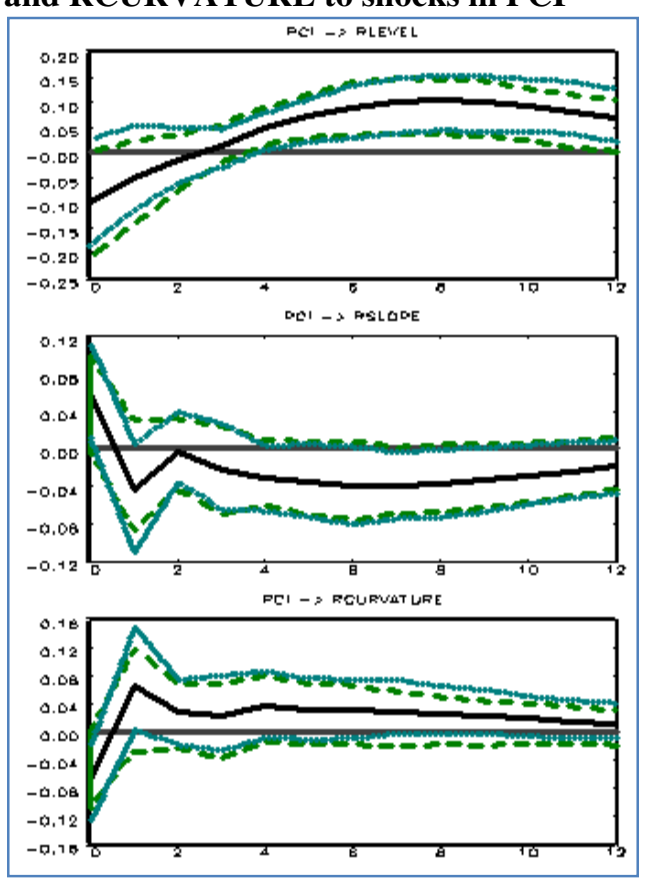

Panel B - Response of PCI to shocks in RLEVEL, RSLOPE and RCURVATURE

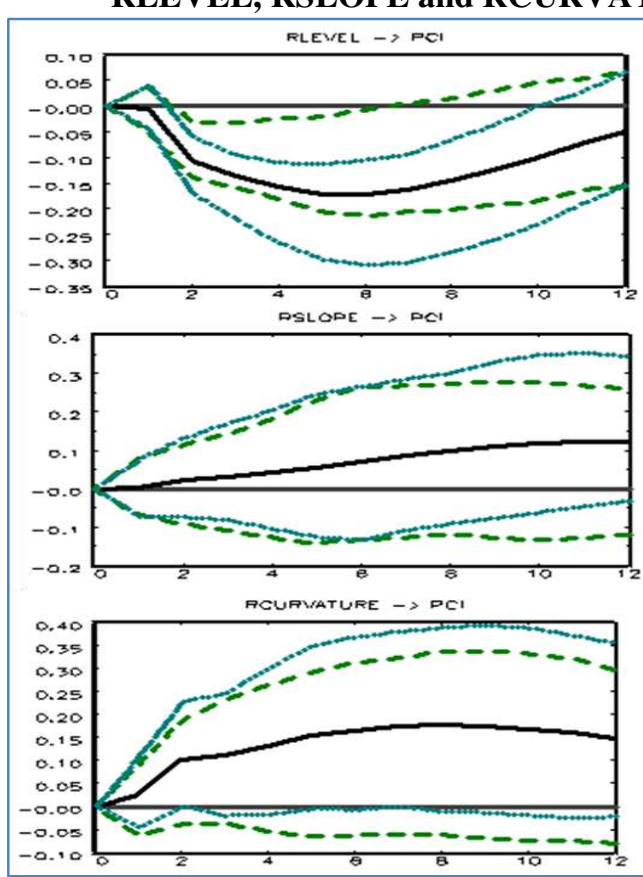

Note: These graphs show the dynamic interactions between the credit spread yield curve's level (RLEVEL), slope (RSLOPE) and curvature (RCURVATURE) and monetary policy (PCI). The bold lines are the impulse responses. The dotted and dashed lines are standard error bands (following Effron and Tibshirani, 1993 and Hall, 1992, respectively).

Table 4: Forecast error variance decompositions for the government yield curve

\begin{tabular}{llllllll}
\hline Months ahead & \multicolumn{7}{c}{ Proportion of forecast error variance accounted by } \\
\cline { 2 - 8 } & IIP & WPI & PCI & NEER & GLEVEL & GSLOPE & GCURVATURE \\
\hline GLEVEL & & & & & & & \\
1 & 0.00 & 0.00 & 0.36 & 0.11 & 0.53 & 0.00 & 0.00 \\
6 & 0.07 & 0.01 & 0.30 & 0.06 & 0.55 & 0.00 & 0.00 \\
12 & 0.14 & 0.01 & 0.24 & 0.05 & 0.56 & 0.00 & 0.00 \\
GSLOPE & & & & & & & 0.00 \\
1 & 0.00 & 0.00 & 0.18 & 0.06 & 0.00 & 0.76 & 0.01 \\
6 & 0.00 & 0.01 & 0.37 & 0.14 & 0.02 & 0.46 & 0.01 \\
12 & 0.01 & 0.01 & 0.42 & 0.10 & 0.15 & 0.30 & 0.79 \\
GCURVATURE & & & & & & & 0.49 \\
1 & 0.00 & 0.00 & 0.16 & 0.05 & 0.00 & 0.00 & 0.34 \\
6 & 0.02 & 0.00 & 0.37 & 0.04 & 0.03 & 0.05 & 0.05 \\
12 & 0.02 & 0.01 & 0.43 & 0.03 & 0.13 & 05 & \\
\hline
\end{tabular}

Note: These tables show the proportion of the forecast error variance of the government yield curve's level (GLEVEL), slope (GSLOPE), curvature (GCURVATURE) as explained by different factors including output (IIP), prices (WPI), monetary policy (PCI) and exchange rate (NEER). 
Table 5: Forecast error variance decompositions for the corporate yield curve

\begin{tabular}{lcccccccc}
\hline Months ahead & \multicolumn{7}{c}{ Proportion of forecast error variance accounted by } \\
\cline { 2 - 8 } & IIP & WPI & PCI & NEER & CLEVEL & CSLOPE & CCURVATURE \\
\hline CLEVEL & & & & & & & \\
1 & 0.00 & 0.00 & 0.06 & 0.04 & 0.89 & 0.00 & 0.00 \\
6 & 0.08 & 0.00 & 0.29 & 0.02 & 0.47 & 0.10 & 0.04 \\
12 & 0.16 & 0.00 & 0.22 & 0.01 & 0.20 & 0.26 & 0.15 \\
CSLOPE & & & & & & & \\
1 & 0.00 & 0.00 & 0.00 & 0.20 & 0.00 & 0.80 & 0.00 \\
6 & 0.01 & 0.00 & 0.21 & 0.14 & 0.12 & 0.46 & 0.06 \\
12 & 0.05 & 0.00 & 0.22 & 0.07 & 0.11 & 0.36 & 0.19 \\
CCURVATURE & & & & & & & \\
1 & 0.00 & 0.00 & 0.00 & 0.03 & 0.00 & 0.00 & 0.97 \\
6 & 0.01 & 0.00 & 0.14 & 0.02 & 0.09 & 0.01 & 0.72 \\
12 & 0.05 & 0.01 & 0.18 & 0.02 & 0.09 & 0.09 & 0.56 \\
\hline
\end{tabular}

Note: These tables show the proportion of the forecast error variance of the corporate yield curve's level (CLEVEL), slope (CSLOPE), curvature (CCURVATURE) as explained by different factors including output (IIP), prices (WPI), monetary policy (PCI) and exchange rate (NEER).

Table 6: Forecast error variance decompositions for the credit spread yield curve

\begin{tabular}{lccccccc}
\hline Months ahead & \multicolumn{7}{l}{ Proportion of forecast error variance accounted by } \\
\cline { 2 - 8 } & IIP & WPI & PCI & NEER & RLEVEL & RSLOPE & RCURVATURE \\
\hline RLEVEL & & & & & & & \\
1 & 0.00 & 0.00 & 0.12 & 0.01 & 0.87 & 0.00 & 0.00 \\
6 & 0.01 & 0.04 & 0.11 & 0.02 & 0.79 & 0.00 & 0.02 \\
12 & 0.09 & 0.06 & 0.25 & 0.02 & 0.54 & 0.00 & 0.05 \\
RSLOPE & & & & & & & \\
1 & 0.00 & 0.00 & 0.03 & 0.03 & 0.00 & 0.94 & 0.00 \\
6 & 0.02 & 0.07 & 0.04 & 0.05 & 0.02 & 0.77 & 0.02 \\
12 & 0.03 & 0.07 & 0.07 & 0.07 & 0.05 & 0.69 & 0.02 \\
RCURVATURE & & & & & & & \\
1 & 0.00 & 0.00 & 0.04 & 0.00 & 0.00 & 0.00 & 0.96 \\
6 & 0.01 & 0.06 & 0.06 & 0.07 & 0.05 & 0.10 & 0.65 \\
12 & 0.01 & 0.05 & 0.07 & 0.10 & 0.07 & 0.10 & 0.60 \\
\hline
\end{tabular}

Note: These tables show the proportion of the forecast error variance of the credit spread yield curve's level (RLEVEL), slope (RSLOPE), curvature (RCURVATURE) as explained by different factors including output (IIP), prices (WPI), monetary policy (PCI) and exchange rate (NEER). 